Florida International University FIU Digital Commons

4-10-1996

\title{
Flexible pavement layer moduli determination : an adaptive artificial neural network approach
}

Michael A. Adeife

Florida International University

DOI: $10.25148 /$ etd.FI13101529

Follow this and additional works at: https://digitalcommons.fiu.edu/etd

Part of the Civil Engineering Commons

\section{Recommended Citation}

Adeife, Michael A., "Flexible pavement layer moduli determination : an adaptive artificial neural network approach" (1996). FIU Electronic Theses and Dissertations. 1137.

https://digitalcommons.fiu.edu/etd/1137 
FLORIDA INTERNATIONAL UNIVERSITY

Miami, Florida

FLEXIBLE PAVEMENT LAYER MODULI DETERMINATION :

AN ADAPTIVE ARTIFICIAL NEURAL NETWORK APPROACH

A thesis submitted in partial satisfaction of the requirements for the degree of

MASTER OF SCIENCE

IN

CIVIL ENGINEERING

by

Michael A. Adeife 
To: Dean Gordon Hopkins

School of Engineering and Design

This thesis, written in full by Michael A. Adeife, and entitled " Flexible Pavement Layer Moduli Determination : An Adaptive Artificial Neural Network Approach", having been approved in respect to style and intellectual content, is referred to you for judgement.

We have read this thesis and recommend that it be approved.

Nii Busby Attoh-Okine

L. David Shen

Sylván C. Jolibois, Jr, Major|Professor

Date of Defense : 10th April, 1996.

The thesis of Michael A. Adeife is approved.

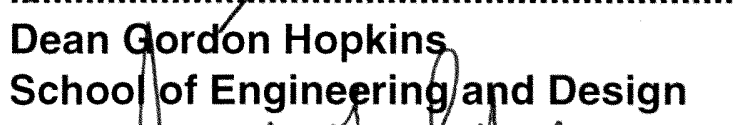

Dr. Richard L. Campbell

Dean of Graduate Studies

Florida International University, 1996 
I dedicate this thesis to my family - my mother, my father and my siblings. Without them this dream would not be a reality. 


\section{ACKNOWLEDGMENTS}

I wish to express my gratitude to the members of my thesis committee Dr. Sylvan Jolibois, Dr. L. David Shen and Dr. Nii Attoh-Okine for their comments and commendations and for expressing so much confidence in me by serving on the committee.

I also would like to thank my colleagues - Liping Wang, Hesham Elbadrawi, Adjo Amekudzi , Gerard Cadet and Gregory Netto for their inspiring words of advice and encouragement.

More special thanks must go to Drs. Jolibois and Attoh-Okine for their initiative in advising me of a suitable research endeavor. Their timely and strong criticisms in addition to their precious words of advice are greatly appreciated.

Most of all, I would like to thank God for his protection and kindness. 


\section{ABSTRACT OF THE THESIS \\ FLEXIBLE PAVEMENT LAYER MODULI DETERMINATION : \\ AN ADAPTIVE ARTIFICIAL NEURAL NETWORK APPROACH \\ by \\ Michael A. Adeife \\ Florida International University, 1996 \\ Dr. Sylvan C. Jolibois, Jr. Major Professor}

The estimation of pavement layer moduli through the use of an artificial neural network is a new concept which provides a less strenuous strategy for backcalculation procedures. Artificial Neural Networks are biologically inspired models of the human nervous system. They are specifically designed to carry out a mapping characteristic. This study demonstrates how an artificial neural network uses non-destructive pavement test data in determining flexible pavement layer moduli. The input parameters include plate loadings, corresponding sensor deflections, temperature of pavement surface, pavement layer thicknesses and independently deduced pavement layer moduli. 
1. INTRODUCTION

1.1 Problem Statement ...................................................... 1

1.2 Background........................................................................... 1

1.2 Objectives of the Study................................................. 5

2. LITERATURE REVIEW

2.1 Pavement Management.................................................... 6

2.2 Deflection Tests .............................................................. 9

2.3 Backcalculation............................................................... 12

2.4 Artificial Neural Networks............................................... 13

3. NON DESTRUCTIVE TESTING AND THE REMAINING LIFE CONCEPT

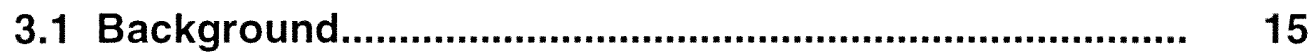

3.2 Pavement Structure Tests................................................. 16

3.3 NDT Pavement Deflection Devices.................................. 17

3.4 Interpreting and Analyzing Deflection.............................. 32

3.5 Fatigue/Damage Theory................................................... 36

3.6 Evaluation of In-Situ Structural Condition........................ 36

3.7 Structural Capacity................................................................ 37

3.8 Remaining Life Concept.................................................. 38

4. ARTIFICIAL NEURAL NETWORKS

4.1 Background...................................................................... 43

4.2 History of Artificial Neural Networks............................... 44 


\section{TABLE OF CONTENTS(contd)}

CHAPTER

4. ARTIFICIAL NEURAL NETWORKS

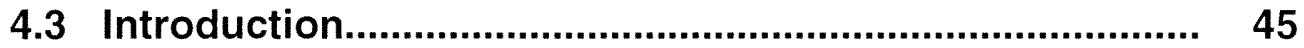

4.4 The Artificial Neuron............................................................. 47

4.5 Characteristics of Artificial Neural Networks.................... 49

4.6 Development of Artificial Neural Networks........................ 57

4.7 Backpropagation Algorithm......................................... 58

4.8 Adaptive Artificial Neural Networks.................................. 61

4.9 Limitations and Misconceptions of ANNs........................ 62

5. BACKCALCULATION

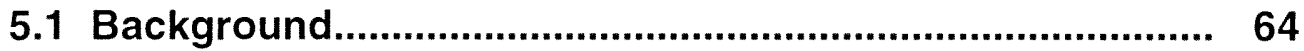

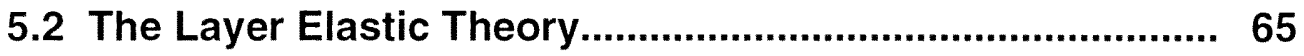

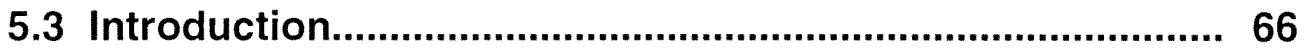

5.4 Layer Moduli Estimation Methods....................................... 67

5.5 Sources of Error in Backcalculation Iteration...................... 69

5.6 Emerging Backcalculation Methods..................................... 74

6. APPLICATION OF ANN TO BACKCALCULATION (THESIS METHODOLOGY)

6.1 Software Selection .............................................................. 75

6.2 Data Collection and Preparation........................................... 77

6.3 Generation of Deflection Basins.......................................... 77

6.4 Network Determination......................................................... 85

7. RESULTS

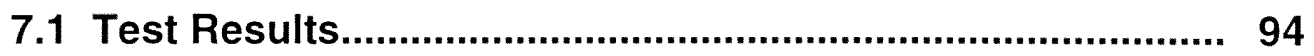


TABLE OF CONTENTS(contd)

CHAPTER

PAGE

7. RESULTS

7.2 Comparison With Traditional Method................................ 98

8. CONCLUSIONS

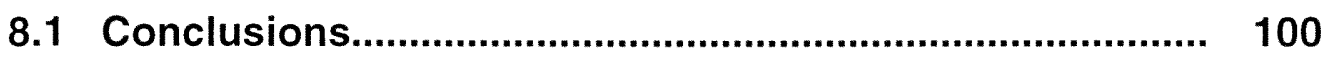

8.2 Study Limitations/Constraints.......................................... 102

8.3 Future Approach................................................................ 103

LIST OF REFERENCES.................................................................... 104

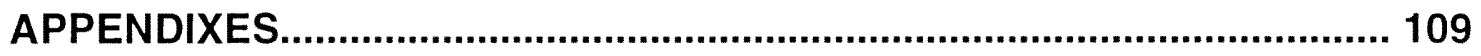




\section{LIST OF TABLES}

1. Table 3.1: Characteristics of Non Destructive Testing Equipments

2. Table 3.2 : Road Rater Models

3. Table 3.3: Summary of Deflection Basin Parameters

4. Table 5.1: Regression Equations For Estimating Layer Moduli

5. Table 5.2 : Prominent Backcalculation Programs

6. Table 6.1: Summary of Results - Generation of Deflection Basins

7. Table 6.2: Neural Network Training Data

8. Table 7.1: Test Results of Layer Moduli for SR 821 NB

9. Table 7.2: ANN Results For Other Pavements

10. Table 7.3: Time Comparison Between ANN and Traditional Method 


\section{LIST OF FIGURES}

1.1 Steps Involved in the PMS Process.

3.1 Dynamic Force Output of Steady State Vibratory Devices

3.2 Location of Sensors in the Dynaflect System.

3.3 Road Rater and Dynamic Loading System.

3.4 Falling Weight Deflectometer

3.5 Location of Circular Plate and Sensors For FWD

3.6 Principle of the Falling Weight Deflectometer

3.7 Deflection Basin

3.8 Structural Capacity With Increased Load and Time

3.9 Curve For Relationship b/w Condition Factor and Remaining Life

4.1 Artificial Neural Network Structure

4.2 The Artificial Neuron

4.3 Single and Multi-Layer Networks

4.4 The Learning Concept Model

4.5 Internal Activation and Transformation

5.1 Elements of Backcalculation Programs

7.1 ANN Architecture For $\mathrm{E}_{\mathrm{ac}}$

7.2 ANN Architecture For $E_{b}$

7.3 ANN Architecture For $\mathrm{E}_{\mathrm{sb}}$ 


\section{Chapter 1}

\section{INTRODUCTION}

\subsection{Problem Statement}

The purpose of a pavement management system is to determine cost effective and savings strategies which must be implemented when available financial resources are limited and must be prudently disbursed.

It is very important that all existing highways be maintained in usable condition. Any procedure developed to improve any one of the various component stages of the pavement management process would be a vital contribution.

\subsection{Background}

The idea of Pavement Management is one that has been in existence for several decades. Based on the intention to provide a theoretical background for 
the extension of the AASHO Road Test, researchers in the United States and Canada initiated a new framework to the existing pavement design by using a system network approach (1).

Haas et al (1) define pavement management as :

"The identification of optimum strategies at various levels as well as the implementation of these strategies. It encompasses processes that cover all activities involved in providing and maintaining pavements at an adequate level of service. These processes range from information acquisition to planning, programming, execution, construction, maintenance and rehabilitation to periodic monitoring of in service pavements. The objective of a pavement management system is to use all these information and decision criteria in an organized framework to produce a cost effective pavement program ".

Sharaf (2), supports this definition and emphasizes that a viable pavement management system would have to include a pavement maintenance management section which focuses on the production and monitoring of a maintenance program. One of the key priorities in the execution of the program is having a network structural condition assessment.

Generally, pavement infrastructure systems worldwide represent a huge investment burden on taxpayers, as such there exists widespread concern over the conditions of these infrastructures. With limited budget allocation, reduced resources and escalating use, it is essential that roadways be adequately managed in order to maintain the vitality of the transportation system. 
Realizing this fact, the Federal Highway Administration (FHWA) (3), set a policy requiring that each state highway agency (SHA) have a working pavement management system based on the concepts described in the AASHTO publication "Guidelines On Pavement Management". As of November, 1994, virtually every state Department of Transportation (DOT) already has at least a framework of an effective pavement management system that is becoming more sophisticated, developed, consistent and less dependent on experienced manpower (4).

The world is currently witnessing an evolution in the use of microcomputers towards many applications and pavement management is not an exception (5). A significant number of state DOTs and highway agencies have developed and implemented several PMSs, including the PAVER, ROADMAN, PARS, WSPMS, RAMS, OPAC, CALTRANS PMS and HDMIII (6).

In a pavement structure the bulk of deformation to the structure occurs as a result of the actions of strains and stresses in the pavement's varying layers. In a flexible pavement for instance, strains at the bottom of the asphalt layer are related to cracking of the asphaltic surface layer, while stresses on the top of the subgrade may cause rutting (7). The elasticity of any material (or soil type) refers to its ability to return to its original form after going through some deformation as a result of an applied point load or continuous loading. The elastic modulus commonly referred to as "modulus" (or sometimes referred to as Young's Modulus) for any material, is simply defined as the stiffness of that material within its elastic range/limit (7). The elastic modulus of any material can be determined as the ratio of 
stress to strain $(\sigma / \epsilon)$. This formula used compute to stresses or strains, can be used in the evaluation of structural capacity and consequently remaining life of a pavement. The non destructive deflection tests (NDT) applied to pavements provide a technique whereby the structural condition of pavements can be analyzed, assessed and evaluated. Based on the elastic layer theory, which has been formulated, refurbished and modified over an expanse of time, the data obtained from the tests are used in the deduction of several parameters which may act as indicators towards determining the in-situ pavement structural condition (7).

Estimating pavement layer modulus is one of the primary procedures of evaluating the overall structural condition of a pavement. Results produced from deflection tests of pavements are used in various procedures to predict pavement life and/or determine overlay thickness requirements.

Artificial Neural Networks(ANN) technology represents a new approach to estimate pavement layer elastic modulus in a backcalculation procedure. Previous research has demonstrated that artificial neural networks have a great potential for automating the non destructive evaluation of pavement condition (8). ANNs offer a number of advantages over the traditional statistical methods, due to their generalization, massive parallelism and most importantly their time saving characteristics (9). ANNs exhibit an algorithm that has been shown to be three orders of magnitude faster than conventional gradient search algorithms.

In addition, the fact that ANNs are also known to be computationally efficient makes them a preferred approach(10). An artificial neural network gains its knowledge 
through a "learning/ training" method where it is exposed to input and output patterns of a set of data. As a result of this learning, networks are able to generalize and effect a relationship between inputs and outputs such that outputs may be deduced for given input sets.

\subsection{Objective of the Study}

I) The overall goal of the study is to apply artificial neural networks in the deduction of pavement layer moduli and perform a comparative analysis of ANN outputs with those of traditional programs.

Specifically to achieve this goal, the research will also:

(a) develop a model which can used as a tool in the evaluation of pavement layer moduli for any given pavement.

(b) identify the most significant variable(s) required for the determination of layer moduli in a backcalculation procedure.

The ultimate benefit to be obtained from this process will be the development of a new technique to backcalculate pavement moduli. 